\title{
DEBATES
}

\section{A participação institucionalizada em tempos de recessão democrática}

\author{
Institutionalized participation in times of democratic recession
}

\author{
Neiara de Morais \\ Maria Andréa Luz da Silva \\ Francisco Horácio Frota da Silva Frota
}

\begin{abstract}
Resumo
$\mathrm{O}$ artigo parte da compreensão da participação institucionalizada no contexto das formas históricas de participação no Brasil nas últimas três décadas, destacando a passagem do momento de entusiasmo inicial, que a incensava como a saída para a revitalização da democracia representativa, para um segundo momento, onde a prática participativa converteu-se, ela mesma, em um problema. Em seguida, aborda as diferentes estratégias governamentais em seu movimento atual de desmonte dos canais de participação na esfera federal, promovendo uma guinada completa na experiência participativa brasileira. Explicitada a encruzilhada política, o artigo desenvolve uma série de argumentos que apontam para a necessidade de resgatar a participação do seu lugar de abandono, no atual cenário de recessão democrática, buscando superar os seus limites e dilemas.
\end{abstract}

\section{Palavras-chave}

Participação; Instituiçóes Participativas; Democracia Participativa.

\section{Abstract}

The article starts from the understanding of institutionalized participation in the context of historical forms of participation in Brazil in the last three decades, highlighting the passage from the moment of initial enthusiasm, which encouraged it as the way out for the revitalization of representative democracy, to a second moment, where participatory practice has itself become a problem. Then, it addresses the different government strategies in its current movement to dismantle participation channels in the federal sphere, promoting a complete turn in the Brazilian participatory experience. Having explained the political crossroads, the article develops a series of arguments that point to the need to rescue the participation of its place of abandonment, in the current scenario of democratic recession, seeking to overcome its limits and dilemmas.

\section{Keywords}

Participation; Participatory Institutions; Participatory Democracy. 


\section{Os desafios da participação}

A redemocratizaçáo do Brasil trouxe para o centro do debate político a participação popular. A Constituição de 1988, conhecida como Constituição Cidadá, incorporou no seu texto as reivindicaçóes dos mais diferentes segmentos sociais. As experiências que se seguiram ao processo de Assembleia Constituinte pareciam caminhar na construçáo de uma sociedade democrática que náo se satisfazia com os limites da representatividade. O que estava em discussão era como superar as iniquidades de uma sociedade elitista, concentradora de renda e herdeira de uma tradição escravocrata.

A história do país mostra que sua elite foi constituída pelos privilegiados economicamente ou os que possuem identidades étnicas raciais mais próximas do branco, do gênero masculino e considerados mais preparadas intelectualmente etc. No que se refere ao processo de construção democrática, o desafio vinha sendo o da contraposição entre a delegação total de ação ou controle das escolhas adotadas e a consequente possibilidade de revisão de tais decisóes. O debate envolvia temas como: democracia e participação; cidadania e participação; governança e participação. $\mathrm{O}$ momento era de substituição de paradigmas, de rutura e mudanças no entendimento do que deveria ser uma democracia.

O Brasil, como outros países da América Latina, estava envolvido no debate e na experiência de construir espaços de participação da sociedade civil. $\mathrm{O}$ significativo era saber que, embora a teoria política hegemônica tivesse restrição a tais possibilidades, o desafio estava sendo lançado. Não importava muito o fato de acreditar ser inviável o aprofundamento da participaçáo numa sociedade complexa mas sim, potencializar o debate sobre a participação e transformá-lo em uma questão importante para a teoria da democracia. (SARTORI,1994)

Os conceitos de democracia e participação estiveram presentes em todos os debates significativos da ciência política do século passado e ainda continuam presentes no século XXI, haja vista a importância que os mesmos adquiriram e ainda adquirem quando do debate sobre os limites da representatividade e sobre os itens referentes à governança. $\mathrm{O}$ debate foi sendo marcado pela reflexão em torno das diferentes relaçóes entre atores participativos, poder executivo, poder legislativo e até mesmo o poder judiciário. Oliveira (1995) analisa os processos ocorridos em tal período, formulando um pensamento no qual haveria uma grande compatibilizaçáo entre o modelo neoliberal ou o projeto neoliberal e as formas de participação. Evelina Dagnino, questionando tal entendimento, lança mão do conceito de confluência perversa 
apontando o problema de uma confluência temporal entre o neoliberalismo e a expansão da participaçáo no lugar de uma coincidência política, um momento em que a participação cidadá passa a ser reivindicada tanto pela reforma neoliberal, como a reforma democratizante. (DAGNINO, 2004).

Passados os primeiros anos de conquistas legais, experimentaçôes e estudos entusiastas, os limites e dilemas da participação começaram a falar mais alto. Em paralelo, setores conservadores, de forma orquestrada, passaram a desferir ataques à participaçáo por entender que ela alcançara patamares que ofereceriam riscos às instituiçôes tradicionais do sistema político. Por certo, essa última visão é a que sai vitoriosa na eleição presidencial de 2018 , de lá para cá, a ação de desmonte das instituições participativas tornou-se muito mais impiedosa.

O presente artigo trabalha, então, com a metáfora de que a participação institucionalizada se encontra acuada, adoecida e, em certa medida, abandonada como um doente sem identificação no leito de um hospital qualquer, e desenvolve o argumento de que, no contexto atual de recessão democrática, a participação deve ser resgatada desse "lugar" para voltar à reflexão e reinvenção pelo campo progressista.

Para isso, o artigo está estruturado em três seçôes, além desta introdução. A primeira seção, intitulada "Participação institucionalizada: de cura à doença da democracia”, apresenta esse percurso, da apologia ao abandono, trazendo o olhar histórico sobre as formas de participação no Brasil (GOHN, 2019), bem como explicitando algumas críticas e dilemas levantados tanto por setores progressistas quanto por conservadores. Em síntese, trará os elementos fundamentais da compreensão do processo participativo de tal período e do questionamento que ocorre na retração de tais processos.

A segunda seção apresenta o panorama de desmonte de um amplo conjunto de instituições participativas a partir da ação do governo federal, ação essa que vem sendo implementada explicitamente por meio de decretos, mas também pelo movimento duplo: i) aguardar que os conselhos desapareçam por abandono, eximindo-se de praticar quaisquer atos necessários ao funcionamento dos colegiados e ii) corroer por dentro as estruturas da participação até que percam o sentido.

A terceira e última seção, apresenta argumentos para a defesa da tese de que a participação deve ser assumida como um tema ou, seguindo a metáfora, "um doente" do campo progressista, não só pela sua paternidade, mas acima de tudo porque não abandonamos a ideia de que é preciso democratizar a elaboração e o controle das 
políticas e que os grandes dilemas revelados pelos anos de experimentaçóes participativas podem e devem ser enfrentados.

\section{Participação institucionalizada: de cura à doença da democracia}

Os debates sobre a construçáo e qualidade da democracia se realizaram num contexto de desconfiança e desvalorizaçáo da democracia representativa. Experiências envolvendo a sociedade civil no processo de decisáo política se multiplicaram como alternativa aos limites da representação.

O quadro participativo da sociedade civil foi sendo formado por fóruns sociais, orçamentos participativos, conselhos, conferências, assembleias e plenárias, mobilizaçóes em torno de pautas sobre gênero e raça, movimentos étnicos, culturais, religiosos etc..

As críticas e dificuldades da democracia, portanto, não se tornaram impedimentos para a participação cidadã nas questóes públicas em variadas frentes, institucionais ou náo, haja vista que a força da democracia participativa, combinou mecanismos da democracia representativa com outros da democracia direta.

As reflexóes caminharam no sentido de perceber que em torno do conceito de participação estavam questóes de ordem objetiva e subjetiva, de natureza normativa e comportamental, coletivas e individuais. A conquista de uma democracia participativa impôs práticas individuais e coletivas de um novo tipo. O Brasil avançava nos debates sobre a construção e a qualidade da sua democracia. Conquistas no processo participativo já poderiam ser contabilizadas na sua legislaçáo. Uma boa síntese para retroceder na história e melhor perceber o tema deste artigo é a contribuição que nos fornece Maria da Glória Gohn (2019) ao elencar ciclos de formas históricas de participação no Brasil nas últimas cinco décadas. Seu esforço teórico lança o olhar para atores envolvidos, suas demandas, as respostas do poder público, o locus dessa ação, a cultura política resultante desses processos, seus avanços e retrocessos. Mas sua contribuição se torna ainda mais importante pelo propósito de tomar a participação de forma ampla, "incluindo e articulando a participação da população na sociedade civil (em movimentos, organizaçóes, coletivos, protestos etc.) e a participaçáo de representantes da população e agentes públicos em instâncias institucionalizadas, normatizadas por órgãos estatais" (GOHN, 2019, p. 13). 
Se pensarmos a participação no Brasil sob o ponto de vista que Gohn (2019) nos oferece, percebemos que, desde o que a autora denomina de $3^{\circ}$ ciclo $^{1}$ (participação na década de 1980: Diretas Já e o processo constituinte) e $4^{\circ}$ ciclo (nova fase da participação institucionalizada ou cidadá pós-1988), há um deslocamento da ideia de participação autônoma e "de costas para o Estado" para a ideia de participação ligada à gestão pública compartilhada. A princípio, tomando-se a movimentação durante a Constituinte, esse giro se dá no campo da reivindicação e, posteriormente à Constituição de 1988, como exercício prático.

Assim, do movimento pelo voto direto às mobilizaçóes de diferentes grupos organizados durante a Constituinte, o centro do debate sobre a democratizaçáo do Estado passava pelo fortalecimento da participaçáo e do controle social das políticas. Em certa medida, a Constituição Federal de 1988 acolheu a reivindicação, o que levou à promulgação de diversas leis posteriores com a marca da participação, a exemplo do Estatuto da Criança e do Adolescente (1990), Lei Orgânica da Saúde (1990), Lei Orgânica da Assistência Social (1993) e Estatuto da Cidade (2001).

A fase que se segue é de tentativa de implementar as conquistas legais e fica marcada pela entrada formal da sociedade civil nas discussões sobre políticas públicas. Isso levou muitas organizaçóes a alterar, ou ampliar, seu repertório de ação. Anteriormente dedicadas à assessoria comunitária ou movimentos de pressão política por direitos, organizaçóes da sociedade civil também passaram a desempenhar um novo papel na participação institucionalizada, envolvendo-se diretamente nas discussóes sobre planejamento, orçamento, gestão, elaboração e controle de políticas públicas.

Durante os anos 2000, tivemos a proliferação das chamadas "instituiçóes participativas", assim entendidas as formas diferenciadas de incorporação de cidadãos e associaçôes da sociedade civil na deliberação sobre políticas (AVRITZER, 2008), especialmente no período 2003-2010, que corresponde aos dois mandatos consecutivos do presidente Luiz Inácio Lula da Silva, do Partido dos Trabalhadores (PT). Nesse

\footnotetext{
${ }^{1} \mathrm{Na}$ elaboração de Gohn (2019), o $1^{\circ}$ clico histórico da participação no Brasil corresponde à década de 1960, e vai da explosão do povo nas ruas, principalmente estudantes e trabalhadores nos primeiros anos da década, à resistência à repressão após o golpe militar. Já o $2^{\circ}$ ciclo histórico, na década de 1970, é marcado por açóes de resistência sob a conjuntura de forte controle imposta pelo AI5 e, ao mesmo tempo, pelo surgimento de organizaçóes populares em bairros e periferias dos grandes centros urbanos em torno de lutas por direitos sociais básicos.
} 
período, o país contava com 59 conselhos nacionais e chegou a realizar 74 conferências nacionais, nas quais se estima que mais de 5 milhôes de pessoas tenham sido envolvidas (SOUZA, 2011). Vale lembrar que esses dados excluem as experiências locais de participação, postas em marcha por meio de orçamentos participativos, planos diretores participativos e, por certo, conferências e conselhos estaduais e municipais.

A crise da representatividade vivida pelas democracias parecia minimizada com a participaçáo cidadã e a sociedade civil organizada desempenhava papel importante na sua relação com o Estado. Embora sem a pretensão de substituir a estruturas existentes, mas influindo nas decisões políticas, não só através da escolha dos que decidem ou dos partidos que estão no poder, como também por meio da pressão social, da ação direta e dos canais institucionais de diálogo e deliberação compartilhada.

Nos documentos que regulamentam os diversos organismos de governo vinha se tornando comum a ênfase na necessidade de uma prática institucional colaborativa, participativa e intersetorial. No entanto, tal mudança de paradigma tinha dificuldades de se efetivar na maioria dos casos. As avaliaçóes do período registravam o desejo em busca de efetivação do novo paradigma. O mais comum, em todos os níveis da administração pública, ainda era o trabalho setorial e a defesa dos princípios e das práticas de cada grupo a partir das suas verdades e experiências.

A literatura especializada, nesse mesmo período, já havia iniciado uma onda de produçóes acadêmicas com uma tônica bem diferente do ufanismo inicial. Alguns setores dos movimentos sociais e a teoria crítica alertavam para os perigos da pasteurização e domesticação dos processos participativos, cooptação de organizaçóes sociais, os problemas da representação no interior das instituiçôes participativas e uso da participaçáo para legitimar as políticas públicas já desenhadas pelo poder público (DAGNINO, 2004; MILANI, 2008; MIGUEL, 2004, 2010, 2017; MENDONÇA et al., 2009; GURZA LAVALLE, 2011).

Embora fora do escopo deste artigo, não há como não mencionar o impacto das chamadas "Jornadas de Junho": 2013 foi o ano das ruas. As manifestaçóes, inicialmente dirigidas ao aumento do preço dos transportes públicos em Sáo Paulo, rapidamente se espalharam pelo país e a pauta foi expandida para a má qualidade dos serviços públicos em geral para, em seguida, tornarem-se difusas e até mesmo antagônicas. $\mathrm{O}$ retorno às ruas marca também o momento em que fomos lembrados que os sentidos de uma manifestação, ou onda de manifestaçôes, também estão em disputa e, além disso, que as ruas não comportam apenas mobilizaçóes por mais democracia e direitos. 
Para Gohn (2019, p.109), há um certo consenso entre analistas que as manifestaçóes de 2013 no Brasil "surgiram na esteira de outros movimentos de indignados em várias partes do globo, contra as políticas asfixiantes da globalização econômica neoliberal", alguns exemplos disso são: Occupy nos Estados Unidos; Primavera Árabe; revoltas contra a austeridade e precarização do trabalho em Portugal, Grécia e Espanha. Porém, na segunda metade da década de 2010, vimos que, embora tivessem em comum o locus (as ruas) e as convocaçóes pelas redes sociais digitais, os manifestantes tinham valores ideológicos e campos políticos diversos. De uma forma ou de outra, a tônica volta a ser a autonomia em relação aos governos e o rechaço às estruturas tradicionais como partidos, sindicatos ou mesmo movimentos sociais verticalizados. O perfil predominante deixa de ser o militante e passa a ser o de ativista, muitas vezes organizados em "coletivos", que, ao contrário dos movimentos e outras formas mais tradicionais "são agrupamentos fluidos, fragmentados, horizontais, e muitos têm a autonomia e a horizontalidade como valores e princípios básicos (GOHN, 2019, p. 111)".

Para a discussão aqui proposta, o ponto mais relevante é que o clima generalizado de insatisfação não atingiu apenas governos, partidos, instituições ou a democracia representativa, atingiu também, embora de maneira indireta, as instituiçóes participativas que, de certa forma, tinham passado a caracterizar o modo petista de governar na sua versão federal.

Porém, a insatisfação com os espaços híbridos de deliberação e controle das políticas não existia apenas nos setores progressistas, muito pelo contrário. A participação institucionalizada, apontada por alguns como limitada e limitante, para os conservadores parecia já ter ido longe demais. Seus argumentos podem ser vistos nas justificativas $^{2}$ contidas em projetos de decreto legislativo que os partidos de oposição apresentaram no parlamento nacional para tornar sem valor jurídico o decreto da presidenta Dilma Rousseff que instituía o Sistema Nacional de Participação Social (SNPS) em 2014.

O Decreto da Participação, como ficou conhecido, não criava nada muito novo, mas tentava proporcionar organicidade à miríade de mecanismos participativos existentes no país. Ainda assim, contra ele foram utilizados os seguintes argumentos

\footnotetext{
${ }^{2}$ Ver justificativas em: Projeto de Decreto Legislativo (PDC) n. 1.491, do Democratas (DEM) (MENDONÇA FILHO, 2014); PDC n. 1.492, do Partido Popular Socialista (PPS) (BUENO, 2014); e PDC n. 1.494, do PSDB.
} 
pela ala conservadora no parlamento: a) Favorecendo a participaçáo da sociedade civil e dos movimentos sociais, o decreto deixaria em segundo plano o cidadáo comum, não afeto a esse tipo de ativismo social; b) $\mathrm{O}$ decreto é a expressão da pretensão do governo federal de implodir a democracia representativa, transforma o legislativo em um elefante branco e transfere o debate institucional para segmentos eventualmente cooptados pelo próprio governo; e c) O decreto pretende dar voz aos movimentos sociais cooptados pelo atual governo, perpetrando sua influência mesmo na hipótese de mudanças institucionais.

Deve-se levar em conta que o Decreto da Participação ${ }^{3}$ veio à tona já em meio ao profundo acirramento político que culminou no golpe parlamentar que destituiu a presidenta Dilma Rousseff, mas o certo é que, em meio ao bombardeio entre setores progressistas e conservadores, a participaçáo restou praticamente sem defesa e o decreto tornou-se sem efeito. Nas produçóes acadêmicas, o tema da participaçáo institucionalizada foi concentrando-se nos estudos sobre gestão pública, onde surgia esquálida, tímida, como que reduzida a um vago princípio da "boa governança" ou mesmo mera técnica de gestáo, uma vez que dissociada de seus aspectos políticos e relaçôes com a democracia.

Estamos agora em uma encruzilhada política. A participação institucionalizada, incensada inicialmente como a cura para a "doença" da democracia representativa, para alguns converteu-se, ela mesma, em doença.

\footnotetext{
${ }^{3}$ Uma busca no Google com a expressão "Decreto 8.243/2014” (o Decreto da Participação) apresenta como primeira palavra complementar a opção "ditadura", isso porque a tônica defendida pelos meios de comunicação foi a de que o decreto extinguiria a democracia. O debate em torno do Decreto da Participação é um excelente exemplo para compreender a criação do ambiente que levaria ao golpe parlamentar que retirou a presidenta Dilma do seu cargo em 2016.
} 


\section{O desmonte das instâncias participativas}

A eleição de Jair Bolsonaro, no final de 2018, representa uma guinada completa na experiência participativa brasileira. Chegava ao poder não apenas um bloco ultraconservador sem compromisso com democracia ${ }^{4}$, mas alguém disposto a destruir o que já fora implementado.

Já empossado, em março de 2019, durante um jantar com lideranças conservadoras em Washington (EUA), o presidente Jair Bolsonaro disse aos presentes (NÓS TEMOS..., 2019) que o sentido de seu governo não é construir coisas para o povo brasileiro, mas desconstruir. Depois dessa etapa, na sua visão, é que chegaria o momento de começar a fazer algo pelo país. $\mathrm{Na}$ avaliaçáo de Bolsonaro, o Brasil caminhava "para o socialismo, para o comunismo", mas esse processo foi interrompido com a sua vitória eleitoral, em suas palavras: "O Brasil não é um terreno aberto onde nós pretendemos construir coisas para o nosso povo. Nós temos é que desconstruir muita coisa. Desfazer muita coisa. Para depois nós começarmos a fazer" (NÓS TEMOS..., 2019).

Desconstruir é o verbo. Agir no presente para firmar outra narrativa do passado e condicionar o futuro. Portanto, a lógica do governo federal na gestão Bolsonaro é guiada pelas ideias de desmonte, extinção, destruição, aniquilamento. Não é à toa que a marca de 100 dias do governo Bolsonaro foi comemorada, entre outras coisas, com a publicaçáo do Decreto no 9.759/2019, normativa que tinha como objetivo extinguir e alterar as regras de criação e funcionamento de colegiados da administraçáo pública federal. A manifestação conservadora do novo governo ganhou corpo ao extinguir conselhos, comitês e comissóes de âmbito federal com presença significativa da sociedade civil em sua estrutura.

O referido decreto definiu que a partir daquele ato seriam extintos os colegiados instituídos por decreto, por ato normativo ou de outros colegiados, não sendo afetados aqueles criados a partir de $1^{\circ}$ de janeiro de 2019 , ou seja, durante o próprio governo Bolsonaro. O Decreto no 9.759/2019 atingiu diretamente um total de 2.593 colegiados, sendo 996 ligados a instituiçóes federais de ensino, 734 criados por atos

\footnotetext{
${ }^{4}$ Pulemos a necessidade de uma lista de exemplos de manifestaçôes da falta de apreço à democracia com a reprodução da fala emblemática do presidente em janeiro de 2021: "Nós, militares, somos o último obstáculo para o socialismo. Quem decide se um povo vai viver na democracia ou na ditadura são as suas Forças Armadas".
} 
internos do governo federal e 863 sem ato de criação identificado. O quadro abaixo apresenta exemplos de colegiados atingidos pelo decreto:

Quadro 1 - Exemplos de colegiados extintos pelo Dec. 9759/2019

\begin{tabular}{|l|}
\hline Conselho Nacional de Combate à Discriminação e Promoção dos Direitos de LGBT \\
\hline Comissão Nacional de Florestas (Conaflor) \\
\hline Comissão Nacional para Erradicação do Trabalho Escravo (Conatrae) \\
\hline Conselho Nacional de Políticas sobre Drogas (Conad) \\
\hline Conselho Nacional dos Direitos do Idoso (CNDI) \\
\hline Conselho da Transparência Pública e Combate à Corrupção (CTPCC) \\
\hline Conselho das Cidades (Concidades) \\
\hline Conselho Nacional dos Direitos da Pessoa com Defciência (Conade) \\
\hline Conselho Nacional de Desenvolvimento Rural Sustentável (Condraf) \\
\hline Conselho Nacional de Proteção e Defesa Civil (Conpdec) \\
\hline Conselho de Recursos da Previdência Social (CRPS) \\
\hline Conselho Nacional de Segurança Pública (Conasp) \\
\hline Conselho de Relaçóes do Trabalho (CRT) \\
\hline Comissão Nacional de Erradicação do Trabalho Infantil (Conaeti) \\
\hline Comissão Nacional da Biodiversidade (Conabio) \\
\hline Comissão Nacional de Desenvolvimento Sustentável dos Povos e Comunidades Tradicionais \\
\hline Comissão Nacional de Política Indigenista (CNPI) \\
\hline Comissão Nacional de Agroecologia e Produção Orgânica (CNAPO) \\
\hline Comitê Gestor da Internet no Brasil (CGI.br) \\
\hline
\end{tabular}

Fonte: Adaptação de quadro produzido pela Agência de Notícias Rede Brasil Atual - RBA/2019.

Foram mantidos, no entanto, 32 conselhos consultivos, número que representa apenas $1,2 \%$ do total de colegiados ligados à administraçáo federal, como afirma o Ministério da Economia. Os colegiados de universidades federais foram preservados. Aos que sobraram após o tsunami do decreto foram impostas diversas restriçóes como: redução do número de representantes da sociedade civil; redução do número de encontros dos colegiados; aplicação da forma remota das reuniôes dos colegiados; adiamento de Conferências Nacionais já agendadas sem prazo para realização.

Dessa vez, diversas personalidades públicas, parlamentares e representantes de organizaçôes da sociedade civil ou movimentos, manifestaram-se por meio de notas públicas ou pronunciamentos. Vale destacar alguns exemplos: 
O governo segue em sua cruzada para desarticular a sociedade e impedir a participação e fiscalizaçáo dos cidadáos, retirando do povo o poder que a Constituição lhe garante. (...) Agora, com a extinção de conselhos importantes para a formulação de políticas públicas. Como temos visto, o governo prefere se mover em meio à névoa, para que não haja transparência ou cobrança da população $\mathrm{O}$ líder da oposiçáo na Câmara, deputado Alessandro Molon (PSB/RJ) ${ }^{5}$.

$\mathrm{O}$ tema é de grande complexidade e gravidade, com um número elevado de brasileiros que sofrem com as drogas, principalmente os jovens. Essa situação demanda um esforço que só poderá ter resultados com o envolvimento da sociedade civil, estudiosos e especialistas para o enfrentamento do problema, com o aprofundamento do debate sobre açóes e políticas efetivas sobre drogas. Comissáo Especial de Segurança Pública da OAB Nacional ${ }^{6}$.

Por meio da participaçáo de especialistas e da sociedade civil, o papel do Conad é permitir uma discussão visando à construção de políticas públicas capazes de enfrentar o problema das drogas, que atinge parte da populaçáo brasileira. A nova composição do conselho, portanto, exclui as entidades das decisóes políticas na área. Conselho Federal de Enfermagem ${ }^{7}$

Impedir a participação do Serviço Social e de outras categorias profissionais da saúde dos debates do Conad é, sem dúvida alguma, uma tentativa de calar a opiniáo técnico-científica de profissionais que têm apontado caminhos alternativos para a questão das drogas no país. Conselho Federal de Serviço Social (CFESS) ${ }^{8}$

Três meses após a sua publicação, o decreto foi submetido à apreciação do Supremo Tribunal Federal por meio de uma açáo judicial movida pelo Partido dos Trabalhadores (PT). Apesar da expectativa de que o Tribunal o barrasse totalmente, a decisão cautelar foi pela suspensão apenas parcial do decreto9. Para a maioria do Supremo, a medida presidencial náo poderia atingir colegiados previstos em leis ou por elas mencionados, já aqueles criados por decreto, ou outro ato normativo infralegal, o

\footnotetext{
${ }^{5}$ Entrevista à Jornalista Claudia Mota do Caderno de Política da Rede Brasil Atual - RBA em 12 do 04 de 2019.

${ }^{6}$ Nota de repudio publicada pela Jornalista Gabriela Coelho no site Consultor Jurídico em 22 de julho de 2019.

7 Trecho da Nota da COFEN sobre à retirada da Enfermagem do Conselho Nacional de Políticas sobre Drogas publicada em 23 de julho de 2019.

8 Trecho retirado da Nota de repúdio do Conselho Federal de Serviço Social sobre à retirada da participação popular do CONAD.

${ }^{9}$ A decisão ocorreu em sessão extraordinária realizada no dia 12/06/19, onde a maioria (por 5 votos a 4 ) dos ministros acolheu medida cautelar na Ação Direta de Inconstitucionalidade (ADI) 6.121, impetrada pelo PT (BRASIL, 2019a).
} 
STF julgou que não existe impedimento para que o chefe do Executivo determine, também por meio deste mecanismo, sua extinção.

A tentativa explícita de extinguir os conselhos e demais colegiados foi parcialmente barrada por via judicial, mas isso não foi suficiente para impedir o desmonte. O governo segue apostando em duas estratégias: i) aguardar que os conselhos desapareçam por abandono, ou seja, eximir-se de praticar quaisquer atos necessários ao funcionamento dos colegiados, inclusive a nomeação de seus representantes e ii) corroer por dentro as estruturas da participação até que percam o sentido, o que pode ser feito por meio da não disponibilização de recursos, esvaziamento das reunióes e pautas, sucessivas alteraçóes na composição, uso do conselho para legitimar decisóes apenas do governo etc. As duas estratégias podem ser utilizadas isolada ou simultaneamente. Vejamos, a título de ilustração, o caso do Conselho Nacional de Políticas sobre Drogas (Conad).

O Conad foi criado em 2006 e contava com participação de representantes da Ordem dos Advogados do Brasil (OAB), Conselho Federal de Medicina (CFM), Conselho Federal de Psicologia (CFP), Conselho Federal de Serviço Social (CFESS), Conselho Federal de Enfermagem (Cofen), Conselho Federal de Educação (CFE), a Uniāo Nacional dos Estudantes (UNE) e a Sociedade Brasileira para o Progresso da Ciência (SBPC). O Conad contava, ainda, com a participação de cinco profissionais antes indicados pelos ministros que presidiam o conselho: um jornalista, um antropólogo, um representante da classe artística e dois representantes de entidades do terceiro setor. Pela antiga regulamentação, esses cinco assentos deviam ser ocupados por "profissionais ou especialistas, de manifesta sensibilidade na questão das drogas".

Em julho de 2019, outro decreto presidencial, o Decreto 9.926, reduziu de 31 para 14 o número de integrantes do colegiado e excluiu representaçóes da sociedade civil e especialistas. Dali em diante o Conselho seria composto apenas por representantes do governo e dos conselhos estaduais antidrogas. O decreto estabelece ainda que fica "vedada a divulgação de discussóes em curso" pelo Conad "sem a prévia anuência do Ministro de Estado da Justiça e Segurança Pública e do Ministro de Estado da Cidadania”. Por meio do seu site oficial, a UNE comentou a medida:

Mesmo após ter sofrido uma derrota no Supremo Tribunal Federal ao tentar extinguir uma série de conselhos e fóruns consultivos que ligavam a sociedade civil às políticas públicas, o governo continua tentando aos poucos afastar os cidadãos desses espaços. "Ampliar o debate sobre as drogas no Brasil é bandeira da UNE. É uma questão que deve ser tratada 
do ponto de vista da saúde pública e também do ponto de vista do problema social do tráfico. Excluir agentes que possam contribuir com esses conhecimentos é um retrocesso sem tamanho", afirmou o presidente da UNE Iago Montalvão. (POR ORDEM..., 2019).

O caso do Conad vem à tela apenas ilustrar o processo de desmonte, poderia ter sido usado o Conselho do Meio Ambiente, da Criança e do Adolescente ou muitos outros. O que aqui se quer destacar é que, para além dos ataques explícitos levados a cabo por meio de decretos, ambas as estratégias - abandono e corrosáo, como citado acima - estão sendo utilizadas, isolada ou simultaneamente, com bons resultados para a extinção dos canais de participação.

\section{Participação, um tema que deve voltar à reflexão do campo progressista}

Resgatando a metáfora do enfermo que vem sendo usada na construçáo deste artigo, talvez seja a hora de assumir o paciente como "nosso", ou seja, encarar a questão da participação nas políticas como um problema do campo progressista, mesmo que, para alguns, a decisão seja pela eutanásia. Olhar para essas experimentaçóes democráticas de maneira crítica, mas também sem procurar nelas a salvação para todos os males da democracia, tomando-as pelo que são, espaços formais de diálogo, negociação e, em alguns casos, compartilhamento de poder com a esfera governamental, espaços de vocalização e defesa de demandas geradas em outros espaços sociais.

Por outras palavras, assumir a participaçáo como um tema do campo progressista náo apenas porque ali foi gerado, mas, sobretudo, porque não abandonamos a ideia de que é preciso democratizar a elaboração e o controle das políticas. Isso porque a construção da experiência brasileira de participação institucionalizada tem uma marca distintiva que a vincula às políticas públicas (AVRITZER, 2008; GOHN, 2019).

Para tanto, é preciso resgatar a participação do lugar de mera "técnica arrojada de planejamento público” ou, como diz Milani (2008):

Fazer participar os cidadãos e as organizaçôes da sociedade civil (OSC) no processo de formulação de políticas públicas foi transformado em modelo da gestão pública local contemporânea. A participação social, também conhecida como dos cidadãos, popular, democrática, comunitária, entre 
os muitos termos atualmente utilizados para referir-se à prática de inclusão dos cidadãos e das OSCs no processo decisório de algumas políticas públicas, foi erigida em princípio político-administrativo. (...) Com base em fontes diversas, constrói-se o "princípio participativo", apoiado por atores tão diversos quanto o Banco Mundial, a OCDE, a União Europeia, as Naçôes Unidas, muitas organizaçôes não-governamentais e integrantes do Fórum Social Mundial (ROJO, MILANI E ARTURI, 2004; MILANI E KERAGHEL, 2005). É evidente que daí decorrem questionamentos críticos acerca do significado e do fundamento da participação social nos diferentes contextos (MILANI, 2008, p.554).

Mais que um somatório de instituiçóes e procedimentos, a participação, enquanto ideia, envolve muito mais que isso, envolve a luta contra a desigualdade, a exclusão, a opressão, envolve o permanente debate sobre as relaçôes Estado/sociedade, envolve, enfim, o debate sobre a democracia.

E não será possível pensar em soluções sem antes entender melhor o problema. Erramos ao reivindicar maior poder formal de decisão e controle das políticas públicas? Erramos no desenho dos mecanismos que levariam a esse resultado (conselhos, conferências, orçamento participativo etc.)? Erramos ao ocupar os espaços reivindicados, uma vez que faltariam "pernas" para outras açôes? Ou, ainda, teríamos errado na forma como ocupamos esses espaços?

Não será possível também que, a partir da experiência brasileira, algumas questóes levantadas sobre os limites da participaçáo institucionalizada estejam, na verdade, mais ligadas às contradiçôes que nascem de uma certa identificação política entre pautas sociais e o governo de plantão? Ou, o que seria bem mais complexo, estamos dizendo que as três décadas de experimentaçóes de instituiçôes participativas nos ensinaram que sua própria ideia geradora contém um equívoco, isto é, a formalização dos espaços de compartilhamento de poder entre Estado e sociedade civil não contribui para o enfrentamento à desigualdade, ampliação de direitos, formação política e democratização das políticas públicas, uma vez que, necessariamente, sufocariam, moldariam ou arrefeceriam as pautas sociais?

Para contribuir com essa discussão, elegemos dialogar, dentre outros, com o artigo emblemático de Luiz Felipe Miguel (2017) "Resgatar a participação: democracia participativa e representação política no debate contemporâneo”. Para o autor, a grande aposta em uma democracia renovada pela participação popular, realizada no Brasil nas últimas décadas, foi frustrada. Por um lado, porque a exaltação inicial da abordagem 
participacionista partia de "percepçóes demasiado ingênuas" e, por outro, porque o exercício dessa participação foi, ao longo do tempo, reduzindo as exigências normativas associadas à ampliação dos mecanismos participativos.

Há um descompasso entre o entusiasmo com que foram acolhidos os espaços participativos por aqueles que desejam uma democracia aprofundada e o quão pouco essa participação ressemantizada de fato foi capaz de desafiar a reproduçáo dos padrôes de dominação entranhados nas estruturas políticas vigentes (MIGUEL, 2017, p.84).

Para o autor, dois aspectos da experiência brasileira recente teriam contribuído para tal resultado: i) a redução da participaçáo à esfera do Estado, que teve como foco a distribuição do investimento público e deixou a esfera privada fora do alcance da decisão democrática; e ii) a diluição da fronteira entre participação e representaçáo, uma vez que a promessa de participaçáo direta inicial transmudou-se em estruturas representativas paralelas, tudo sob a chancela da literatura teórica participacionista.

O primeiro aspecto levantado por Miguel (2017), sobre a incapacidade das experiências participativas em adentrar nas esferas de reprodução dos padróes de dominação, nos leva, na verdade, às grandes questôes da democracia na atualidade. Para alguns autores, o que vivemos hoje é o esgotamento da democracia na sua versão liberal. Ellen Wood (2003) afirma que o capitalismo redefiniu a democracia, reduzindo-a aos parâmetros do liberalismo, deixando intocada, e intocável, toda uma esfera de dominação criada pelo capitalismo por meio, principalmente, da transferência de poderes do Estado para a sociedade civil, a propriedade privada e o mercado. Assim, para a autora, a esfera do poder econômico teria se expandido para muito além da capacidade de enfrentamento da democracia e, consequentemente, não é possível falar do triunfo da democracia liberal, mas sim, que ela se aproximou dos seus limites.

Esse é um aspecto fundamental, se a expectativa inicial era de que a participação fosse capaz de renovar e fortalecer a democracia a ponto de fazer frente a esse processo, podemos concluir que fracassou tremendamente. No entanto, talvez sejamos, pelo menos, capazes de avaliar em profundidade os grandes acontecimentos dos últimos anos (Golpe de 2016 e eleição de Bolsonaro em 2018) e sua relação de causalidade com tensionamentos provocados pelos esforços de combate à desigualdade e ampliação da democracia. Enfrentar esse processo neoliberal selvagem de desigualdade e exclusão é o horizonte da participação, seja ela institucionalizada ou não. Porém, até agora, no 
embate quem tem recuado é a democracia liberal, ainda assim, não nos parece que estejamos dispostos a renunciar a ela.

O segundo aspecto levantado por Miguel (2017) prende-se ao problema da representação nas instituições participativas. Para o autor, os analistas não tardaram a perceber que a promessa de participaçáo direta no processo decisório encobria uma estrutura representativa paralela, no entanto:

Em vez disso levar a uma avaliação mais elaborada das potencialidades e dos limites dessas novas instituiçóes, conduziu a uma renúncia crescente ao ideal de presença direta na tomada de decisóes, estimulada por uma literatura teórica que se empenha em apagar a distinção entre representação e participação" (MIGUEL, 2017, p. 85).

O problema teria se agravado com a chegada do PT ao governo federal, quando a ênfase na participaçáo passa a ser os conselhos e conferências setoriais de políticas públicas nas diversas instâncias de governos, em detrimento, por exemplo, de experiências abertas à participação direta de cidadáos e que, nessa fase, dá-se uma mudança no sentido da participação almejada, que deixa de ser a participação popular para ser a de organizaçóes da sociedade civil. Além disso, ainda segundo Miguel (2017), em grande parte das arenas, assumem a posição de representantes da sociedade civil aqueles que detêm visibilidade ou reconhecimento público, isto é, atributos fornecidos por seus pares, pela mídia ou pelo Estado. Nesse contexto, teria desaparecido a relação representante-base, não havendo qualquer exigência de interlocução válida com representados. Sem essa interlocução perde-se também a relação, o ambiente e o espaço coletivo de construção de preferências políticas, o que coloca em xeque a relação de representação.

O dilema da representação nas instituiçôes participativas é destacado aqui como uma questão não resolvida. Nas sociedades contemporâneas é difícil imaginar processos que possam abrir mão, pelo menos em alguma de suas fases, da representação, mas isso não faz com que possamos perder de vista as preocupaçóes com a qualidade democrática dessa representação e, mais do que isso, com a ampliação dos espaços de participaçấo direta. Esse é, portanto, um dos pontos de debate que não podemos abandonar ao repensar a participação.

Em que pese às questóes levantadas, são também numerosas as razóes pelas quais o debate sobre a participação, agora num contexto de recessão democrática, deve ser retomado. Em primeiro lugar, porque náo se pode perder de vista que os processos 
participativos não se dão apenas no âmbito federal, onde não só a permeabilidade é menor, como o ataque explícito vem se dando. Atualmente, existem diversos governos locais e estaduais abertos ao compartilhamento de poder com experiências em curso que também devem ser criticadas, repensadas e potencializadas. Experiencias, por exemplo, no norte e nordeste do país indicam a possibilidade de participação na gestáo de Fundos Setoriais, Escolas Formativas de Conselheiros, Planos Decenais, Funcionamento dos Conselhos e outras experiencias de governança com forte presença da sociedade civil.

Além disso, voltando a pensar no âmbito federal, embora não seja possível determinar a exata causalidade, o período de implementação das instituiçóes participativas coincide sim com uma série de conquistas sociais, melhoria nas políticas, políticas mais inclusivas e redução das desigualdades (GOHN, 2019; POCHMANN, 2010; CARVALHO, 2018). Precisamos entender essas relaçóes antes de abandonar a ideia da participação. Além das pesquisas no campo acadêmico, temos indício do seu potencial emancipador, inclusive, porque se ele não existisse, o governo Bolsonaro e o campo conservador não estariam tão empenhados em destrui-la.

Em estudo sobre como os movimentos sociais se inserem no processo de produção das políticas públicas e as condiçóes que favorecem ou limitam sua influência na modelagem das políticas, Tatagiba et al (2018) trabalham o argumento de que os resultados que alcançam estão condicionados por três elementos: as características do regime, as características dos subsistemas das políticas e as características dos movimentos sociais. As características do regime tratam da permeabilidade dos governos às demandas e propostas dos diferentes atores societários, entre os quais os movimentos sociais. Logo, quanto maior a incompatibilidade entre os elementos do projeto de governo e os modelos alternativos de políticas públicas dos movimentos, menores as oportunidades para influenciarem as políticas públicas. Ainda assim, essa permeabilidade também pode variar de acordo com as características do subsistema de política no qual o movimento está inserido e do lugar que ocupam (central ou periférico) nas redes do subsistema: 
O resultado, em termos de conformação de uma política pública, surge da produção, experimentação e difusão de ideias por parte de movimentos sob condiçóes estruturadas, por um lado, pelas configuraçôes de regimes e subsistemas e, por outro, pela capacidade dos movimentos sociais para transformar as condiçóes em que atuam e confrontar outros atores e redes que constroem, experimentam e defendem modelos de políticas públicas distintos (TATAGIBA et al, 2018, p. 114).

Nesse processo de revisão das potencialidades da participação cidadã, será necessário considerar que, enquanto espaço formal de interação sociedade/poder público, as instituiçôes participativas poderão cumprir diferentes papéis no contexto de recessão democrática, ainda mais se consideramos as diferenças entre os vários subsistemas das políticas (TATAGIBA et al, 2018). Esses papéis levarão em conta uma série de fatores, tais como: existência ou não de retaguarda legal para garantir poder de decisão; caráter deliberativo ou consultivo; correlação de forças; estado do tema na agenda pública; existência de interlocutores mais permeáveis no interior das burocracias etc.

Por exemplo, a estratégia “participação em conferências” poderá assumir papéis diferentes de acordo com o subsistema de política ao qual se vincula. No caso da área da saúde, as conferências têm um valor histórico, simbólico e político imenso, já para outras áreas, as conferências não terão o mesmo papel e outras açóes poderão ser empreendidas. De forma que, a maneira como as organizaçóes e movimentos sociais vão relacionar-se com as instituiçóes participativas, que conseguiram resistir aos ataques até agora realizados pelo governo central, será variada. Mais do que isso, esses espaços poderão, e deverão ser ressignificados. Se outrora foram propícios aos debates sobre as políticas e mostraram-se porosos às demandas, hoje podem converter-se em espaços privilegiados de fiscalização, vigilância e denúncia sobre a ação pública, por exemplo.

Um aspecto de suma importância nos é trazido por CARLOS et al (2017) sobre estudos baseados nas interaçóes entre movimentos e estado via instituiçóes. Para as autoras, movimentos sociais não podem ser reduzidos analiticamente à política do confronto, por três razóes:

Primeira: os movimentos sociais se engajam em um conjunto de atividades que não necessariamente implicam a relação de conflito com os detentores de poder: em sociedades complexas movimentos também cooperam com o estado, colaborando na elaboração e implementação de políticas governamentais (GIUGNI e PASSY, 1998; CARLOS, 2012). Segunda: os 


\begin{abstract}
movimentos sociais combinam uma pluralidade de formas de relação com o estado em modelos híbridos e criativos que promovem a articulação circunstancial entre ação institucionalizada e não institucionalizada (ABERS, SERAFIM e TATAGIBA, 2014; CARLOS, 2012; DOWBOR, 2012). Terceira: o uso de canais institucionalizados no repertório de ação e a formalização das organizaçôes não leva obrigatoriamente à desmobilização do movimento (CARLOS, 2012; DOWBOR, 2012). (CARLOS et al, 2017. p.362).
\end{abstract}

Trata-se de uma perspectiva sobre institucionalização da açáo coletiva que permite incorporar nas análises as instituiçóes e os atores do sistema político e explorar a diversidade de interaçóes entre os movimentos e o estado. Não é preciso escolher uma única via de ação política e nela apostar todas as fichas, porque a participação é plural, se dá dentro e fora da institucionalidade, simultaneamente.

Em suma, vivemos um contexto adverso, de retrocesso democrático e baixa permeabilidade no governo federal para as demandas dos movimentos sociais. Não podemos pensar na participação institucionalizada como uma saída para todos os males da democracia (nunca foi, muito menos será agora em tempos de retrocesso), mas, exatamente por isso, talvez seja a hora de experimentar e inventar novos parâmetros para o exercício da participação institucionalizada.

Sabemos também que nossa ação para incidir na formatação e controle social das políticas precisa de espaços formais de diálogo com os governantes, não apenas pela necessidade de construção de consensos ou negociaçóes, mas porque esses espaços podem ser convertidos também em locais privilegiados para dar visibilidade aos dissensos e conflitos.

\title{
A título de conclusão
}

No atual momento devemos ser capazes de avaliar em profundidade os grandes acontecimentos dos últimos anos. Rever as potencialidades da participação cidadá enquanto espaço formal de interaçáo sociedade/poder público e verificar a existência, ou não, de causalidade com os conflitos provocados pelos esforços de combate à desigualdade e ampliação da democracia.

Na possibilidade de a participação cidadã cumprir diferentes papéis no contexto de recessáo democrática é necessário saber se existe um padrão de participação e de organização da sociedade civil nas distintas regióes do país. As experiências do Consórcio Nordeste no momento da pandemia favorecendo o planejamento intergovernamental; as participações na gestão de Fundos Setoriais, nas Escolas 
Formativas de Conselheiros, nos Planos Decenais, no Funcionamento dos Conselhos e outras experiências com forte presença da sociedade civil, podem ajudar a compreender os elementos potencializadores do processo participativo. Reflexão, portanto, que pode contribuir no entendimento de como as formas de participaçáo apontam sua relevância para a articulação das políticas nacionais.

O estudo de tais experiências deve se voltar para as preocupaçôes com a qualidade democrática dessa representação e, mais do que isso, com a ampliação dos espaços de participação direta. Esses papéis deverão levar em conta uma série de fatores, tais como: existência ou não de retaguarda legal para garantir poder de decisão; caráter deliberativo ou consultivo; correlação de forças; estado do tema na agenda pública; existência de interlocutores mais permeáveis no interior das burocracias etc.

Democratizar a elaboração e controle das políticas e fortalecer a formação política pautada na ideia de que "participar se aprende participando" seguem sendo objetivos importantes. Não são objetivos que abandonamos após tantos ciclos de participação no Brasil (GOHN, 2019), por isso, resumindo os argumentos levantados ao longo deste artigo, precisamos resgatar a participação do seu "lugar de abandono", voltar a experimentar, pesquisar, refletir sobre as críticas já apontadas, rever o dilema da representação no interior das instituiçôes participativas, encontrar meios para ampliar os espaços de participaçáo direta etc. Tudo isso pode ser feito sem que tenhamos que abrir mão das conquistas formais de participação que os ciclos anteriores alcançaram, mas buscando ressignificá-las com os novos atores, açôes e meios que dispomos hoje.

Neiara de Morais é Doutora em Democracia no Século XXI pela Universidade de Coimbra / Portugal e Professora Visitante do Programa de Pós-Graduação em Políticas Públicas da Universidade Estadual do Ceará - UECE. E-mail: neiara.morais@gmail com.

- Maria Andréa Luz da Silva é Mestra em Políticas Públicas e Sociedade e Professora do Programa de Pós-Graduação em Políticas Públicas da Universidade Estadual do Ceará - UECE e Coordenadora do Núcleo de Pesquisas Sociais da UECE - NUPES. Email: andrealuz.ce@gmail.com. 
Francisco Horácio Frota da Silva Frota é Doutor Sociologia pela Universidade Salamanca / Espanha, Coordenador do Programa PósGraduação em Políticas Públicas da Universidade Estadual do Ceará - UECE e do Núcleo de Pesquisas Sociais da UECE - NUPES. E-mail: fhsfgm@gmail.com.

\section{Referências}

AVRITZER, Leonardo. Instituiçóes participativas e desenho institucional: algumas consideraçóes sobre a variação da participação no Brasil democrático. Opinião Pública, v. 14, n. 1, p.43-46, jun. 2008. Disponível em: <https://www.scielo.br/scielo.php?script=sci_arttext\&pid=S010462762008000100002>. Acesso em: 12 dez. 2020.

AVRITZER, Leonardo. Impasses da democracia no Brasil. Rio de Janeiro: Civilização Brasileira. 2016. BOBBIO, Norberto. O futuro da democracia: uma defesa das regras do jogo. 2. ed. Rio de Janeiro: Paz e Terra, 1986.

BRASIL. Supremo Tribunal Federal. Medida Cautelar na Açâo Direta de Inconstitucionalidade 6.121, de 12 de junho de 2019. Distrito Federal, 2019a. Disponível em: <http://www.stf.jus.br/arquivo/cms/noticiaNoticiaStf/anexo/ADI6121votoMMA.pdf>. Acesso em: 02 jan. 2021.

BRASIL. Decreto No 9.926, de 19 de julho de 2019. Dispóe sobre o Conselho Nacional de Políticas sobre Drogas. Brasília, DF, 2019b. Disponível em: <http://www.planalto.gov.br/ccivil_03/_ato20192022/2019/decreto/D9926.htm>. Acesso em: 15 dez. 2020.

BRASIL. Decreto $N^{0}$ 9.759, de 11 de abril de 2019. Extingue e estabelece diretrizes, regras e limitaçóes para colegiados da administração pública federal. Brasília, DF, 2019c. Disponível em: <https:/www.in.gov.br/materia/-/asset_publisher/Kujrw0TZC2Mb/content/id/71137350>. Acesso em: 15 dez. 2020.

BRASIL. Decreto $N^{0}$ 8.243, de 23 de maio de 2014. Institui a Política Nacional de Participação Social - PNPS e o Sistema Nacional de Participação Social - SNPS e dá outras providências. Brasília, DF, 2014. Disponível em: <http:/www.planalto.gov.br/ccivil_03/_Ato20112014/2014/Decreto/D8243.htm>. Acesso em: 15 dez. 2020.

BRASIL. Lei n. 10.257, de 10 de julho de 2001. Regulamenta os arts. 182 e 183 da Constituição Federal, estabelece diretrizes gerais da política urbana e dá outras providências. Brasília, DF, 2001. Disponível em: <http://www.planalto.gov.br/ccivil_03/LEIS/LEIS_2001/L10257.htm>. Acesso em: 15 dez. 2020 . 
BRASIL. Lei n. 8.742, de 7 de dezembro de 1993. Dispõe sobre a organização da Assistência Social e dá outras providências. Brasília, DF, 1993. Disponível em: <http://www.planalto.gov.br/ccivil_03/leis/18742compilado.htm>. Acesso em: 15 dez. 2020.

BRASIL. Lei n. 8.069, de 13 de julho de 1990. Dispóe sobre o Estatuto da Criança e do Adolescente e dá outras providências. Brasília, DF, 1990a. Disponível em: <http://www.planalto.gov.br/ccivil_03/leis/18069.htm>. Acesso em: 15 dez. 2020.

BRASIL. Lei n. 8.080, de 19 de setembro de 1990. Dispóe sobre as condiçôes para a promoção, proteção e recuperação da saúde, a organização e o funcionamento dos serviços correspondentes e dá outras providências. Brasília, DF, 1990b. Disponível em: <https://www.prattein.com.br/home/images/stories/Saude/Lei-org-saude.pdf>. Acesso em: $15 \mathrm{dez}$. 2020 .

BRASIL. Constituiçáo da República Federativa do Brasil, de 5 de outubro de 1988. Brasília, DF, 1988. BUENO, Rubens. Projeto de Decreto $N^{0}$ 1.492, de 23 de maio de 2014. Susta o Decreto no 8.243, de 23 de maio de 2014, que "Institui a Política Nacional de Participação Social - PNPS e o Sistema Nacional de Participação Social - SNPS, e dá outras providências". Brasília, DF. 2014. Disponível em: $<$ https://www.camara.leg.br/proposicoesWeb/fichadetramitacao?idProposicao=617824>. Acesso em: 15 dez. 2020.

CARLOS, Euzeneia; DOWBOR, Monika; ALBUQUERQUE, Maria do Carmo Alves. Movimentos sociais e seus efeitos nas políticas públicas: balanço do debate e proposiçóes analíticas. Civitas, v. 17, n. 2, p. 360-378, maio/ago. 2017. Disponível em: <https://revistaseletronicas.pucrs.br/ojs/index.php/civitas/article/view/25925>. Acesso em: 20 dez. 2020.

CARVALHO, Laura. Valsa brasileira. São Paulo: Todavia, 2018.

CFESS. Nota de repúdio à retirada da participação popular do CONAD. Brasília, DF, 22 jul. 2019. Disponível em: <http://www.cfess.org.br/visualizar/noticia/cod/1596>. Acesso em: 15 dez. 2020.

COELHO, Gabriela. OAB defende importância de especialistas para o debate antidrogas no Conad. Consultor Jurídico, 22 jul. 2029. Recuperado de: <https://www.conjur.com.br/2019-jul-22/oabdefende-importancia-especialistas-debate-antidrogas >. Acesso em: 02 jan. 2021.

COFEN. Enfermagem é retirada do Conselho Nacional de Políticas sobre Drogas. Brasília, DF, 23 jul. 2019. Disponível em: <http://www.cofen.gov.br/enfermagem-e-retirada-do-conselho-nacional-depoliticas-sobre-drogas_72564.html>. Acesso em: 15 dez. 2020.

COMPARATO, Fábio. A nova cidadania. Lua Nova, n. 28-29, p. 85-106, 1993.

DAGNINO, Evelina. Confluência perversa, deslocamentos de sentido, crise discursiva. In: GRIMSON, Alejandro (Comp.). La cultura en las crisis latinoamericanas. Buenos Aires: CLACSO, 2004. p. 195216. <http://bibliotecavirtual.clacso.org.ar/ar/libros/grupos/grim_crisis/11Confluencia.pdf>. Acesso em: 10 dez. 2020.

GOHN, Maria da Gloria. Participação e democracia no Brasil. Da década de 1960 aos impactos pósjunho de 2013. São Paulo: Vozes, 2019.

GURZA LAVALLE, Adrian; VERA, Ernesto Isunza. A trama da crítica democrática: da participação à representação e à accountability. Lua Nova, n. 84, p. 353-364, 2011. 
KAEFER, Alfredo. Projeto de Decreto N 1.494 , de 23 de maio de 2014. Susta o Decreto no 8.243, de 23 de maio de 2014, que "Institui a Política Nacional de Participação Social - PNPS e o Sistema Nacional de Participação Social - SNPS, e dá outras providências. Brasília, DF, 2014 Disponível em: <https://www.camara.leg.br/proposicoesWeb/prop_mostrarintegra?codteor=1263201>. Acesso em: 15 dez. 2020.

MIGUEL, Luís Felipe. Resgatar a participação: democracia participativa e representação política no debate contemporâneo. Lua Nova, n. 100, p. 83-118, 2017. Disponível em: <https://www.scielo.br/pdf/ln/n100/1807-0175-ln-100-00083.pdf>. Acesso em: 10 jan. 2021.

MIGUEL, Luís Felipe. Representação e interesses: uma crítica a Young e Urbinati. In: ENCONTRO DA ABCP, 7., 2010, Recife. Anais do VII Encontro da ABCP. Recife, 2010. Disponível em: <http://cienciapolitica.servicos.ws/abcp2010/arquivos/11_7_2010_18_13_58.pdf>. Acesso em: 26 fev. 2015.

MIGUEL, Luís Felipe. Democracia e a crise da representação política: a accountability e seus impasses. 2004. Disponível em: <http://www.ces.uc.pt/lab2004/pdfs/LuisFelipeMiguel.pdf>. Acesso em: 26 fev. 2015.

MILANI, Carlos R.S. O princípio da participação social na gestão de políticas públicas: uma análise de experiências latina-americanas e europeias. Revista da Administração Pública, v. 42, n. 3, p. 551-579, maio/jun. 2008.

MENDONÇA, Patrícia Maria et al. Desafios e dilemas das ONGs na cooperação internacional: uma análise da realidade brasileira. Gestão.Org: Revista Eletrônica de Gestão Organizacional, n. 7, p. 6983. 2009.

MENDONÇA FILHO, José. Projeto de Decreto $N^{0}$ 1.491, de 23 de maio de 2014. Institui a Política Nacional de Participação Social - PNPS e o Sistema Nacional de Participação Social - SNPS e dá outras providências. Brasília, DF. 2014. Disponível em: <https://www.camara.leg.br/proposicoesWeb/fichadetramitacao?idProposicao=617737>. Acesso em: 15 dez. 2020.

MOTTA, Cláudia. Decreto de Bolsonaro extingue canais de participação social em políticas públicas. Rede Brasil Atual, 12 abr. 2019. Disponível em: <https:/www.redebrasilatual.com.br/politica/2019/04/decreto-de-bolsonaro-extingue-orgaos-departicipacao-popular/>. Acesso em: 02 jan. 2021.

NÓS TEMOS é que descontruir muita coisa, diz Bolsonaro durante jantar. Valor Econômico, 18 mar. 2019. Disponível em: <https://valor.globo.com/brasil/noticia/2019/03/18/nos-temos-e-quedesconstruir-muita-coisa-diz-bolsonaro-durante-jantar.ghtml>. Acesso em: 02 jan. 2021.

POR ORDEM de Bolsonaro, sociedade civil e especialistas são excluídos do Conad. União Nacional dos Estudantes - UNE, São Paulo, 22 jul. 2019. Disponível em: $<$ https://www.une.org.br/noticias/por-ordem-de-bolsonaro-sociedade-civil-e-especialistas-saoexcluidos-do-conad/>. Acesso em: 02 jan. 2021.

POCHMANN, Márcio. Desenvolvimento, trabalho e renda no Brasil: avanços recentes no emprego e na distribuição de rendimentos. São Paulo: Fundação Perseu Abramo, 2010.

SANTOS, Boaventura de Sousa. Participatory Budgeting in Porto Alegre: Toward a Redistributive Democracy. Politics and Society, n. 4, p. 461-510, 1998. 
246 | Neiara de Morais, Maria Andréa Luz da Silva e Francisco Horácio Frota da Silva Frota

SARTORI, Giovanni. A teoria da democracia revisitada. São Paulo: Ática, 1994.

SOUZA, Cloves Henrique Leite. Mapeamento das experiências participativas. In: SOUTO, Ana Luiza Salles; PAZ, Rosângela Dias Oliveira; MORONI, José Antônio (Eds.). Arquitetura da participação no Brasil: avanços e desafios. Brasília, DF: Instituto POLIS; INESC, 2011. p. 42-93. Disponível em: <https://www.abong.org.br/final/download/relatorioparticipacao.pdf>. Acesso em: 10 dez. 2020.

OLIVEIRA, Francisco. Elegia para um re(li)gião. São Paulo: Paz e Terra, 1995.

TATAGIBA, Luciana.; ABERS, Rebeca Neaera; SILVA, Marcelo Kurant. Movimentos sociais e políticas públicas: ideias e experiências na construção de modelos alternativos. In> PIRES, Roberto; LOTTA, Gabriela; OLIVEIRA, Vanessa (Orgs). Burocracia e políticas públicas no Brasil: interseçôes analíticas. Brasília: Ipea/Enap, 2018. p. 105-140. Disponível em: <http://repositorio.ipea.gov.br/bitstream/11058/8601/1/Movimentos.pdf>. Acesso em: 05 jan. 2021.

WOOD, Ellen Meiksis. Democracia contra o capitalismo: a renovação do materialismo histórico. (P. C. Castanheira, Trad.). São Paulo: Boitempo, 2003.

Texto recebido em 30 de janeiro de 2021. Aprovado em 07 de abril de 2021. 